OPEN ACCESS

Edited by:

Antonio Pisani,

University of Rome Tor Vergata, Italy

Reviewed by:

Pedro J. Garcia-Ruiz,

Fundacion Jimenez Diaz, Spain

Giovanni Defazio,

University of Bari, Italy

*Correspondence:

Maria Fiorella Contarino

m.f.contarino@/umc.nl;

Marina A. J. Tijssen

m.a.j.de.koning-tijssen@umcg.nl

Specialty section: This article was submitted to Movement Disorders, a section of the journal

Frontiers in Neurology

Received: 24 October 2016 Accepted: 25 January 2017 Published: 24 February 2017

Citation:

Contarino MF, Van Den Dool J, Balash Y, Bhatia K, Giladi N,

Koelman JH, Lokkegaard A,

Marti MJ, Postma M, Relja M,

Skorvanek M, Speelman JD,

Zoons E, Ferreira JJ, Vidailhet $M$, Albanese A and Tijssen MAJ (2017) Clinical Practice: Evidence-Based

Recommendations for the

Treatment of Cervical Dystonia with Botulinum Toxin.

Front. Neurol. 8:35

doi: 10.3389/fneur.2017.00035

\section{Clinical Practice: Evidence-Based Recommendations for the Treatment of Cervical Dystonia with Botulinum Toxin}

\author{
Maria Fiorella Contarino ${ }^{1,2 *}$, Joost Van Den Dool3,4, Yacov Balash ${ }^{5,6}$, Kailash Bhatia ${ }^{7}$, \\ Nir Giladi ${ }^{5,6}$, Johannes H. Koelman ${ }^{8}$, Annemette Lokkegaard ${ }^{9}$, Maria J. Martitio, \\ Miranda Postma ${ }^{8}$, Maja Relja ${ }^{11}$, Matej Skorvanek ${ }^{12,13}$, Johannes D. Speelman ${ }^{8}$, \\ Evelien Zoons ${ }^{8}$, Joaquim J. Ferreira ${ }^{14}$, Marie Vidailhet ${ }^{15,16,17,18,19}$, Alberto Albanese ${ }^{20,21}$ \\ and Marina A. J. Tijssen ${ }^{3 *}$
}

${ }^{1}$ Department of Neurology, Haga Teaching Hospital, The Hague, Netherlands, ${ }^{2}$ Department of Neurology, Leiden University Medical Centre, Leiden, Netherlands, ${ }^{3}$ Department of Neurology AB 51, University Medical Centre Groningen, Groningen, Netherlands, ${ }^{4}$ ACHIEVE Centre of Expertise, Faculty of Health, Amsterdam University of Applied Sciences, Amsterdam, Netherlands, ${ }^{5}$ Movement Disorders Unit of the Department of Neurology, Tel Aviv Sourasky Medical Center, Tel Aviv, Israel, ${ }^{6}$ Sackler Faculty of Medicine, Tel Aviv University, Tel Aviv, Israel, ' $5 o b e l l$ Department, Institute of Neurology, National Hospital for Neurology, University College London, London, UK, ${ }^{8}$ Department of Neurology/Clinical Neurophysiology, Academic Medical Center, Amsterdam, Netherlands, ${ }^{9}$ Department of Neurology, Copenhagen University Hospital Bispebjerg, Copenhagen, Denmark, ${ }^{10}$ Department of Neurology, Hospital Clinic i Universitari, Institut D'Investigacio Biomedica August Pi i Sunyer (IDIBAPS), CIBERNED, Barcelona, Spain, "11 Movement Disorders Center, Department of Neurology, Clinical Medical Center School of Medicine, Zagreb University, Zagreb, Croatia, ${ }^{12}$ Department of Neurology, P. J. Safarik University, Kosice, Slovakia, ${ }^{13}$ Department of Neurology, University Hospital of L. Pasteur, Kosice, Slovakia, ${ }^{14}$ Clinical Pharmacology Unit, Faculty of Medicine, Instituto de Medicina Molecular, University of Lisbon, Lisbon, Portugal, ${ }^{15}$ Sorbonne University, UPMC Paris-6, Paris, France, ${ }^{16}$ Brain and Spine Institute - ICM, Centre for Neuroimaging Research - CENIR, UPMC UMR 1127, Paris, France, ${ }^{17}$ INSERM U 1127, Paris, France, ${ }^{18} \mathrm{CNRS}$ UMR 7225, Team Control of Normal and Abnormal Movement, Paris, France, ${ }^{19}$ Department of Neurology, Salpêtriere Hospital, AP-HP, Paris, France, ${ }^{20}$ Department of Neurology, Humanitas Research Hospital, Milano, Italy, ${ }^{21}$ Department of Neurology, Università Cattolica del Sacro Cuore, Milano, Italy

Cervical dystonia (CD) is the most frequent form of focal dystonia. Symptoms often result in pain and functional disability. Local injections of botulinum neurotoxin are currently the treatment of choice for $\mathrm{CD}$. Although this treatment has proven effective and is widely applied worldwide, many issues still remain open in the clinical practice. We performed a systematic review of the literature on botulinum toxin treatment for CD based on a question-oriented approach, with the aim to provide practical recommendations for the treating clinicians. Key questions from the clinical practice were explored. Results suggest that while the beneficial effect of botulinum toxin treatment on different aspects of $C D$ is well established, robust evidence is still missing concerning some practical aspects, such as dose equivalence between different formulations, optimal treatment intervals, treatment approaches, and the use of supportive techniques including electromyography or ultrasounds. Established strategies to prevent or manage common

Abbreviations: ADL, activities of daily living; BoNT, botulinum neurotoxin; $\mathrm{CD}$, cervical dystonia; CMAP, compound muscle action potential; DBS, deep brain stimulation; EMG, electromyography; IU, international units; NAB, neutralizing antibodies; QoL, quality of life; RCTs, randomized controlled trials; SNR, secondary non-responsiveness; SPC, summary of product characteristics; TWSTRS, Toronto Western Spasmodic Torticollis Rating Scale. 
side effects (including excessive muscle weakness, pain at injection site, dysphagia) and potential contraindications to this treatment (pregnancy and lactation, use of anticoagulants, neurological comorbidities) should also be further explored.

Keywords: botulinum toxin, cervical dystonia, recommendations, efficacy, side effects, treatment strategy

\section{INTRODUCTION}

Cervical dystonia $(\mathrm{CD})$ is the most frequent form of focal dystonia, with an overall prevalence of 4.98/100,000 in Europe (1). $\mathrm{CD}$ is characterized by abnormal postures of head and neck that can considerably impair activities of daily living (ADL), with pain occurring in $43.1 \%$ of patients (2). Mood disorders, including anxiety and depression, are frequently present $(3,4)$.

Oral medication has a limited role. Trihexyphenidyl is classically proposed, but the tolerance profile is low (5). Benzodiazepines, especially diazepam and clonazepam, mainly reduce dystonia-related pain, anxiety, and possibly dystonic tremor (6). Tetrabenazine, although possibly effective (7), is limited by the frequent side effect of depression and parkinsonism. Evidence on the effectiveness of allied care treatments, including physiotherapy and cognitive behavioral therapy, is scanty (8). In those with unsatisfactory botulinum neurotoxin (BoNT) effect, surgery may be considered. Peripheral surgery, such as selective peripheral denervation, can provide improvement in about two-thirds of cases, with frequent relapses and is now rarely performed $(9,10)$. Deep brain stimulation (DBS) of the globus pallidus pars interna appears to be a better choice, despite potential severe complications (11). Alternative DBS targets, such as the subthalamic nucleus, need further investigation (12).

Local injections of BoNT are currently the treatment of choice for $\mathrm{CD}$. By binding to peripheral cholinergic nerve endings in the neuromuscular junction, BoNT decreases the release of acetylcholine at the motor neuron in the synaptic cleft, thus blocking neuromuscular transmission and provoking muscle weakness (13).

Botulinum neurotoxin type $\mathrm{A}$ is the most frequently used; type $B$ is only proposed in selected cases.

Although BoNT treatment is widely applied worldwide, many questions remain open in clinical practice.

Some aspects of this treatment have been largely explored in the literature, and robust evidence is available. Other aspects still deserve attention and univocal answers and directives are lacking.

In this paper, literature on BoNT treatment for CD was systematically reviewed based on a question-oriented practical approach. The aim was to provide practical recommendations on common issues in clinical practice.

To this end, we reviewed the evidence concerning the comparison of different formulations of BoNT in improving motor symptoms, pain, and quality of life (QoL), also in relation to the dosage conversion ratio, which is a long debated topic.

Another common issue in the daily practice, which demands stronger evidence is how to prevent and manage side effects and complications, including the formation of neutralizing antibodies
(NAB) and treatment side effects such as dysphagia, neck muscle paresis, or pain at injection site.

Due to the nature of the treatment itself, which involves intramuscular injections and a neurochemical denervation, questions may arise concerning potential contraindications such as the use of anticoagulants or the presence of concomitant neuromuscular disorders, in addition to pregnancy and lactation.

We finally explored issues related to the optimization of the treatment, including the optimal initial dose of BoNT, and whether injection strategy can be improved by applying multiple injection points instead of single injection points or by using neurophysiological techniques or associated physiotherapy. These topics have been touched upon in some studies, but the use of different methodologies, protocols, and sometimes patients populations makes it difficult to directly compare the results.

\section{METHODS}

The aim of this manuscript was to provide a literature review focused on some specific question arising from the clinical practice.

A structured literature review was conducted, by using appropriate keywords covering the topic of BoNT treatment for CD. A language restriction to English, French, German, and Dutch was applied. All kind of studies were reviewed and studies carried out before 1980 were excluded.

\section{Information Sources}

Three databases were searched: Medline and Embase using the Ovid interface, and the Cochrane library.

\section{Selection of Papers}

In all three databases, we identified systematic reviews, randomized controlled trials (RCTs), health economic evaluation studies, and, in both Medline and Embase, also observational studies. The complete search strategy is reported in File S1 in Supplementary Material.

\section{Review Method}

All the papers were screened for topic appropriateness on abstract basis by two independent reviewers with successive agreement on discrepancies. Papers were then assigned to different coauthors according to predefined key clinical questions.

To assess the quality of the published studies, the classification scheme for level of evidence and the level of recommendation of the American Academy of Neurology was used (14) (File S2 in Supplementary Material). The recommendation level is reported for each statement. 


\section{RESULTS}

\section{Effect of Different BoNT Formulations on CD (Table 1)}

Three BoNT-A products are commercially available: onabotulinumtoxinA (Botox ${ }^{\circledR}$, Allergan), abobotulinumtoxinA (Dysport ${ }^{\circledR}$, Ipsen), and incobotulinumtoxinA (Xeomin ${ }^{\circledR}$, Merz). These products differ concerning the added preservatives, the toxin solubility, and the relative potencies. Only one type of BoNT-B is available: rimabotulinumtoxinB (Neurobloc ${ }^{\circledR} /$ Myobloc $^{\circledR}$, Elan Pharma).

\section{Are the Different Formulations of BoNT-A and BoNT-B Effective in Improving CD?}

Several RCTs showed that onabotulinumtoxinA, abobotulinumtoxin $\mathrm{A}$, and rimabotulinumtoxin $\mathrm{B}$ are effective in reducing dystonia when compared to placebo (15-25).

One RCT showed that incobotulinumtoxinA (at both doses of $120 \mathrm{IU}$ and $240 \mathrm{IU})$ significantly improved Toronto Western Spasmodic Torticollis Rating Scale (TWSTRS)-total scores compared to placebo in $233 \mathrm{CD}$ patients (26) and that improvement of mean TWSTRS-total $(p<0.001)$ and severity score $(p<0.016)$ persisted after repeated injection (up to 5) (27).

\section{Conclusion and Recommendations}

There is class I evidence that the three BoNT-A and the BoNT-B formulations significantly improve dystonia in CD. The recommendation level is A for abobotulinumtoxinA,

\begin{tabular}{|c|c|c|}
\hline Question & Answer & $\begin{array}{l}\text { Level of } \\
\text { recommendation }\end{array}$ \\
\hline $\begin{array}{l}\text { Is abobotulinumtoxinA effective in } \\
\text { improving CD? }\end{array}$ & Yes & A \\
\hline $\begin{array}{l}\text { Is incobotulinumtoxinA effective in } \\
\text { improving CD? }\end{array}$ & Yes & B \\
\hline $\begin{array}{l}\text { Is onabotulinumtoxinA effective in } \\
\text { improving CD? }\end{array}$ & Yes & A \\
\hline $\begin{array}{l}\text { Is rimabotulinumtoxinA effective in } \\
\text { improving CD? }\end{array}$ & Yes & A \\
\hline $\begin{array}{l}\text { Does BoNT-A treatment improve } \\
\text { quality of life? }\end{array}$ & Yes & B \\
\hline $\begin{array}{l}\text { Does BoNT-A reduce pain associated } \\
\text { with CD? }\end{array}$ & Yes & A \\
\hline $\begin{array}{l}\text { Do BoNT-A and BoNT-B have a } \\
\text { comparable effect and duration of } \\
\text { effect on dystonia? }\end{array}$ & Yes & A \\
\hline $\begin{array}{l}\text { Do BoNT-A and BoNT-B have the } \\
\text { same rate of side effects? }\end{array}$ & $\begin{array}{l}\text { No (side effects } \\
\text { are more frequent } \\
\text { with BoNT-B) }\end{array}$ & $\mathrm{B}$ \\
\hline $\begin{array}{l}\text { What is the conversion ratio } \\
\text { of onabotulinumtoxinA to } \\
\text { abobotulinumtoxinA? }\end{array}$ & $\begin{array}{l}1 \mathrm{IU} \text { to } 3 \mathrm{IU} \\
1 \mathrm{IU} \text { to } 2.5 \mathrm{IU}\end{array}$ & $\begin{array}{l}A \\
B\end{array}$ \\
\hline $\begin{array}{l}\text { What is the conversion ratio } \\
\text { of onabotulinumtoxinA to } \\
\text { incobotulinumtoxinA? }\end{array}$ & $1 \mathrm{U}$ to $1 \mathrm{U}$ & B \\
\hline
\end{tabular}

BoNT, botulinum neurotoxin; $C D$, cervical dystonia. onabotulinumtoxin $\mathrm{A}$, and rimabotulinumtoxinB, and level $\mathrm{B}$ for incobotulinumtoxinA (26).

\section{Does BoNT-A Treatment Improve QoL?}

In a double-blind RCT, treatment with 500 IU of abobotulinumtoxinA produced significantly greater improvements than placebo in Physical Functioning, Role Physical, Bodily Pain, General Health, and Role Emotional domains of the SF-36 ( $p \leq 0.03$ ) (28).

\section{Conclusion and Recommendations}

There is class I evidence that BoNT-A improves QoL in CD (level B).

\section{Does BoNT-A Reduce Pain Associated with CD?}

In five RCTs with a total of $162 \mathrm{CD}$ patients, $71 \%$ of the patients treated with onabotulinumtoxinA and abobotulinumtoxinA reported pain reduction compared with $12 \%$ of the patients in the placebo group $(p<0.00001)$ (29). Pain was also improved with incobotulinumtoxin A in both single-set injections and long-term treatment $(26,27)$.

\section{Conclusion and Recommendations}

There is class I evidence that BoNT-A reduces pain symptoms in CD (level A).

\section{Do BoNT-A and BoNT-B Have Comparable Effects?}

In two RCTs $(30,31)$, no difference was found in the size and duration of effect on the total TWSTRS score and sub-scores (dystonia severity, limitations, and pain score) between BoNT-A and BoNT-B. Dry mouth and swallowing difficulties were more common with BoNT-B $(30,32)$.

\section{Conclusion and Recommendations}

Botulinum neurotoxin-A and BoNT-B have a comparable effect and duration of effect (level A).

Side effects are more frequent with BoNT-B (class I evidence, level B).

\section{What Is the Conversion Ratio of Different Formulations of BoNT-A?}

The conversion factor between the different formulations is still a matter of discussion.

\section{OnabotulinumtoxinA vs. AbobotulinumtoxinA}

LD50 tests have shown 1:1 potency ratio of incobotulinumtoxinA vs. onabotulinumtoxinA (33), and 2.3:1 of abobotulinumtoxinA vs. onabotulinumtoxinA. These data however cannot be directly translated into the clinical practice (34).

In a retrospective study, changing from onabotulinumtoxin $A$ to abobotulinumtoxin A with a conversion rate of 1:2 resulted in a tendency toward higher efficacy but more adverse events (35). At 6.5 years follow-up, the doses had been reduced, and the median dose conversion ratio had decreased to $1: 1.7$.

In a double-blind study, 79 healthy controls were randomized into 18 groups, receiving different doses and concentrations of onabotulinumtoxinA or abobotulinumtoxinA (36). Both toxins caused a comparable, significant decline in the compound muscle action potential (CMAP). A statistical model with 
CMAP data indicated a bioequivalence of 1 IU onabotulinumtoxinA:1.57 IU abobotulinumtoxinA and a maximum doseequivalence ratio of $1: 3$.

In a comparative clinical study, $73 \mathrm{CD}$ patients were randomized for onabotulinumtoxinA or abobotulinumtoxinA with a dose ratio of 1:3 IU (37). The improvement of Tsui score, the duration of effect, and the rate of side effects were comparable.

Two different conversion factors (1:3 and 1:4) between onabotulinumtoxinA and abobotulinumtoxin A were tested in a double-blind randomized three-period crossover study in 54 CD patients (38). AbobotulinumtoxinA was significantly more effective than onabotulinumtoxin A in reducing Tsui score, with no significant difference between the two conversion ratios. The adverse events were more frequent in the abobotulinumtoxin $\mathrm{A}$ group, but only significantly for the 1:4 conversion.

A recent double-blind, randomized, crossover study using a conversion ratio of 1:2.5 IU showed comparable efficacy and adverse effects (39).

\section{Conclusion and Recommendations}

It is recommended to use a conversion of $1 \mathrm{IU}$ onabotulinumtoxinA to 3 IU abobotulinumtoxinA (level A) $(37,38)$, although conversion ratios of 1:2.5 might be equally safe and effective (class I, level B) (39).

\section{OnabotulinumtoxinA vs. IncobotulinumtoxinA}

In an open label prospective crossover study, 40 patients initially treated with onabotulinumtoxinA were randomly assigned to treatment switch to incobotulinumtoxinA with a 1:1 ratio (33). Inter-injection intervals and treatment duration showed comparable efficacy for at least four injection cycles. Comparable efficacy on TWSTRS and adverse-event profiles for up to 16 weeks were also reported in a randomized, double-blind, parallel-group, non-inferiority trial, with $\mathrm{CD}$ patients randomized to incobotulinumtoxinA or onabotulinumtoxinA with the same conversion factor of $1: 1(40)$.

\section{Conclusion and Recommendations}

It is recommended to use a conversion of 1:1 IU onabotulinumtoxinA to incobotulinumtoxinA (class I, level B).

\section{Optimization of BoNT Treatment for CD (Table 2) \\ What Is the Recommended Initial BoNT Dose for Treatment of CD?}

According to the respective summary of product characteristics (SPC-last accessed 08/04/2015), the suggested starting total dose is $500 \mathrm{IU}$ in two-three muscles, for abobotulinumtoxinA (SPC last text revision 11/12/2013), and <200 IU (50 IU/injection and maximum 100 IU to the sternocleidomastoid) for onabotulinumtoxinA (SPC, 19/03/2015). For incobotulinumtoxinA, a total dose of $200 \mathrm{IU}$ is mentioned, with doses up to $300 \mathrm{IU}$ allowed (50 IU/injection-SPC, 16/11/2012). For rimabotulinumtoxinB, an initial dose of 5,000 IU may be considered, but a dose of 10,000 IU divided between two and four muscles may be more effective (SPC, 26/02/2014).
TABLE 2 | Optimization of BoNT treatment for CD.

\begin{tabular}{|c|c|c|}
\hline $\begin{array}{l}\text { What is the recommended initial dose for } \\
\text { treatment of CD with abobotulinumtoxinA? }\end{array}$ & $\begin{array}{l}500 \text { IU (although other } \\
\text { dosages might be used) }\end{array}$ & $A$ \\
\hline $\begin{array}{l}\text { What is the recommended initial dose for } \\
\text { treatment of CD with incobotulinumtoxinA? }\end{array}$ & $120 \mathrm{IU}$ & $\mathrm{B}$ \\
\hline $\begin{array}{l}\text { What is the recommended initial dose for } \\
\text { treatment of CD with onabotulinumtoxinA? }\end{array}$ & No recommendation & U \\
\hline $\begin{array}{l}\text { What is the recommended initial dose for } \\
\text { treatment of } C D \text { with rimabotulinumtoxinB? }\end{array}$ & $\begin{array}{l}2,500 \text { or } 5,000 \mathrm{IU} \\
10,000 \mathrm{IU}\end{array}$ & $\begin{array}{l}B \\
A\end{array}$ \\
\hline $\begin{array}{l}\text { Can prior polymyographic EMG (pEMG) } \\
\text { and EMG guidance improve the treatment } \\
\text { outcome in treatment-naïve patients? }\end{array}$ & Yes & A \\
\hline $\begin{array}{l}\text { Can prior pEMG and EMG guidance } \\
\text { improve the treatment outcome in patients } \\
\text { with deterioration of treatment effect? }\end{array}$ & Yes & C \\
\hline $\begin{array}{l}\text { Are multiple-points injections per muscle } \\
\text { more effective than single-point injections? }\end{array}$ & Yes & U \\
\hline $\begin{array}{l}\text { Can additional physiotherapy improve the } \\
\text { effect of BoNT treatment? }\end{array}$ & $\begin{array}{l}\text { No (motor improvement } \\
\text { as measured by } \\
\text { TWSTRS or Tsui score) } \\
\text { Yes (disability and pain } \\
\text { and prolongs the effect } \\
\text { of BoNT) }\end{array}$ & $U$ \\
\hline
\end{tabular}

BoNT, botulinum neurotoxin; CD, cervical dystonia; EMG, electromyography; TWSTRS, Toronto Western Spasmodic Torticollis Rating Scale.

In an RCT, 73 patients were randomized into four groups treated with placebo, abobotulinumtoxinA 250, 500, or 1,000 IU, divided between one splenius capitis and the contralateral sternocleidomastoid muscle (21). The greatest improvement was found in the group treated with 1,000 IU, although significantly more side effects were reported. An initial dose of 500 IU abobotulinumtoxinA (divided into 100-200 IU in the sternocleidomastoid muscle, 250-350 IU in the splenius, 100-200 IU in the trapezius, and 100-200 IU in the levator scapulae) significantly improved CD with respect to placebo in another RCT on 68 patients (41). Based on these results, an initial dose of 500 IU abobotulinumtoxinA is suggested. It is worth mentioning, however, that CD could be successfully treated using an average total dose of 200-400 IU abobotulinumtoxinA under electromyography (EMG) guidance, resulting also in fewer side effects (42).

A starting dose of 50-100 IU of onabotulinumtoxinA per muscle, with a maximum dose per session of $280 \mathrm{IU}$, was used in a study on 32 patients. A documented improvement in both subjective and objective parameters was observed in $75 \%$ of patients (43). The mean total doses of original onabotulinumtoxinA injections, reported in 30 studies, as assessed by a systematic review, ranged from 60 to $374 \mathrm{IU}$ in total (44).

In an RCT, both doses of 120 IU and 240 IU incobotulinumtoxinA significantly improved the TWSTRS-total scores compared to placebo in previously treated and treatment-naive subjects, with mild side effects. Initial dose 120 IU of incobotulinumtoxinA has been suggested based on these results (26).

Three double-blind, randomized, placebo-controlled studies $(20,22,23)$ have shown that the effect of botulinum toxin $\mathrm{B}$ 
injections in doses of 2,500,5,000, and 10,000 IU was significantly higher compared to placebo, with the highest clinical effect seen with dose of 10,000 IU as measured by the TWSTRS-total score. The incidence of mild dysphagia was higher in the 10,000 IU group (16, 10, and $27 \%$, respectively, as compared to no patient who received placebo) (20).

\section{Conclusion and Recommendations}

An initial total dose of 500 IU abobotulinumtoxinA is effective (level A), although other dosages might be used $(41,45)$.

An initial total dose of $120 \mathrm{IU}$ incobotulinumtoxinA is probably effective (evidence class I, level B) (26).

No clear recommendations can be given on the optimal starting does of onabotulinumtoxinA (level U).

An initial total dose of 2,500 or 5,000 IU rimabotulinumtoxinB (evidence class I, level B) or 10,000 IU (level A) is probably effective.

\section{Can Prior Polymyographic EMG (pEMG) and Simultaneous EMG Improve the Treatment Outcome?}

In one RCT, $52 \mathrm{CD}$ patients were randomized into a pEMGgroup (treated muscles selected based on clinical evaluation and pEMG, and BoNT injected using simultaneous EMG) or control group (muscles selected based solely on clinical examination and injected without EMG) (46). Improvement on the TWSTRS was higher in the pEMG with EMG assistance group (14 vs. 5\%).

In a randomized prospective, blinded study on 26 treatmentnaive patients, the objectively measured clinical outcome was significantly better when the muscle selection was based on quantitative EMG and treatment was performed with simultaneous EMG, than when treatment was based on clinical judgment alone (47).

Other studies showed that without pEMG, $24-41 \%$ of the dystonic muscles were missed, and $25-35 \%$ of the injected muscles were misjudged as dystonic (47-49).

A retrospective study explored results of treatment with $\mathrm{pEMG}$ in 40 patients with previously unsatisfactory treatment response (50). After 1 year, a significant improvement in both Tsui scores and subjective evaluation was observed. pEMG led to change in injection pattern in $96 \%$ of the patients.

In another study, $8 / 10 \mathrm{CD}$ patients with deterioration of treatment effect, achieved marked improvement (64\% on TWSTRS) after pEMG guided injections (51).

The identification of motor endplate zones with high-density surface EMG may help decreasing the BoNT dose by keeping the effect unaltered (52).

\section{Conclusion and Recommendations}

There is class I evidence that, in treatment-naïve patients, improvements in dystonia and pain are greater if muscles are selected based on a combination of clinical examination and pEMG and injections are performed with EMG guidance (level A) $(46,47)$.

In patients with deterioration of treatment effect, the use of pEMG and EMG guidance can improve the results (class III, level C) $(50,51)$.

\section{Are Multiple-Points Injections per Muscle More Effective than Single-Point Injections?}

No RCTs on this topic were found. A comparative study in 49 patients showed that multiple injections are more effective than a single injection in improving dystonia, pain, posture deformity, range of motion, and activity endurance (53). Experts recommend the administration of one to four injections per muscle, depending on the volume of the muscle $(4,54)$.

\section{Conclusion and Recommendations}

There are indications (class III) that multi-point BoNT injections are more effective than single-point BoNT injections (level U).

\section{Can Physiotherapy Improve the Effect of BoNT Treatment?}

In one single-blind RCT, no significant difference was found between patients randomized to BoNT treatment combined with relaxation therapy alone or with a 12-week physiotherapy program and relaxation therapy (55).

In one crossover RCT on 40 patients, significantly greater reductions in disability in $\mathrm{ADL}$ and subjective pain were observed after a 6-week additional physiotherapy, with respect to BoNT treatment alone. In addition, clinical benefit lasted longer and a lower BoNT dose was needed at reinjection. No significant differences were observed on the Tsui scale and TWSTRS (56).

In a case-control open study, 40 patients followed a 4-week physiotherapy program combined with BoNT treatment or BoNT treatment alone. The physiotherapy group showed significantly more improvement on the pain subscale of the TWSTRS, and on some subscales of the SF-36 (57).

\section{Conclusion and Recommendation}

Adding physiotherapy in combination with BoNT treatment does not produce a greater motor improvement as measured by TWSTRS or Tsui (class II, level C) (55).

Adding physiotherapy to BoNT treatment may improve disability, pain, and prolong the effect of BoNT [class III (4) and IV (57), level U].

\section{Primary and Secondary Non-Responsiveness (SNR) (Table 3)}

Primary non-responsiveness to BoNT, defined as lack of treatment effect from the first application, and due to genetically induced resistance (58) or a prior (unnoticed) botulism (59), is exceptional. Technical aspects such as insufficient dosing, errors during drug storage and reconstitution, or improper injection sites could also lead to an initial lack of response, usually amended in successive treatments.

Secondary non-responsiveness is defined as "insufficiently improved posture after three or more unsuccessful injection cycles in CD patient's previously achieving satisfactory results" (60). SNR concerns around 3-5\% of the patients (61).

The formation of $\mathrm{NAB}$, with estimated frequency in $\mathrm{CD}$ patients varying from $1.2 \%$ (62) to $40 \%$ (63), is one of the causes of SNR. NAB have been found in patients treated with 
TABLE 3 | Primary and SNR.

\begin{tabular}{|c|c|c|}
\hline $\begin{array}{l}\text { Are treatment intervals } \\
<12 \text { weeks safe? }\end{array}$ & $\begin{array}{l}\text { Yes (incobotulinumtoxinA) } \\
\text { No recommendation (rimabotulinumtoxinB, } \\
\text { onabotulinumtoxinA, and abobotulinumtoxinA) }\end{array}$ & $\begin{array}{l}U \\
U\end{array}$ \\
\hline \multirow{4}{*}{$\begin{array}{l}\text { Which treatment } \\
\text { strategies are useful in } \\
\text { case of non-response to } \\
\text { BoNT-A treatment? }\end{array}$} & $\begin{array}{l}\text { Keeping the treatment intervals constant } \\
\text { (early detection of SNR) }\end{array}$ & $U$ \\
\hline & Repeated plasma exchange (contrasting & $U$ \\
\hline & NAB-induced SNR) & \\
\hline & $\begin{array}{l}\text { Switching to BoNT-B produces only } \\
\text { temporary benefit }\end{array}$ & $U$ \\
\hline
\end{tabular}

BoNT, botulinum neurotoxin; NAB, neutralizing antibodies; SNR, secondary nonresponsiveness.

onabotulinumtoxinA, abobotulinumtoxinA, and rimabotulinumtoxinB (64). RimabotulinumtoxinB seems more likely to elicit SNR than BoNT-A: antibody-induced therapy failure was shown in $44 \%$ of CD patients treated with BoNT-B during a short period (65). The development and titer of NAB does not correlate with the entity of SNR, and there is evidence that the mere detection of NAB does not necessarily indicate the presence of SNR $(66,67)$. No antibodies are described after treatment with incobotulinumtoxinA in naive CD patients $(68,69)$, while this has been reported in one patient previously treated with another BoNT (33).

Factors significantly associated with SNR include previous recourse to other therapies such as surgical interventions, physical therapy and neuroleptic use, a higher number of serious adverse events, more frequent treatment interruptions, and higher average BoNT-A doses during the last three injection cycles (67).

\section{Are Treatment Intervals $<12$ Weeks Safe?}

No controlled studies have compared the long-term immunogenicity of different BoNT-A.

In a consensus statement, experts recommend that reinjection is left as long as clinically possible, to minimize the chance of antibody responses (4).

The current manufacturer information suggest that the minimal interval between injections should be 10 (SPC onabotulinumtoxinA and incobotulinumtoxinA) to 12 weeks (SPC abobotulinumtoxin A). This information, however, was based on data obtained with the original formulation of onabotulinumtoxinA, which contained a higher protein load $(70,71)$.

Fixed 3-month intervals may result in a decrease in treatment satisfaction toward the end of the period. Indeed up to $45 \%$ of patients indicated a preference for treatment intervals $\leq 10$ weeks (72).

In a trial with incobotulinumtoxin $A$, where injection sessions were administered at intervals of 6-20 weeks, there were no differences in the tolerability profile in the group of patients injected at 6-14 weeks with respect to the other groups (27).

\section{Conclusion and Recommendations}

There is only one class I study showing that, with incobotulinumtoxinA, treatment intervals $<12$ weeks do not increase the risk of developing antibodies. There is insufficient data to recommend or discourage the use of an interval $<12$ weeks for treatment with
rimabotulinumtoxinB, onabotulinumtoxin $\mathrm{A}$, and abobotulinumtoxinA (level U).

\section{Which Treatment Strategies Are Useful in Case of SNR to BoNT-A Treatment?}

Secondary non-responsiveness develops gradually, starting with a reduced duration of clinical effect and culminating with significant reduction of the maximal effect (73). Therefore, constant treatment intervals and careful scoring of treatment effect may lead to an early detection of SNR (74). However, whether an early detection is useful to prevent the development of SNR and the induction of high titers of NAB is unclear, considering the absence of effective prevention strategies.

Switching from BoNT-A to BoNT-B in patients with SNR due to NAB may initially result in effective treatment; however, most of these patients will eventually develop antibodies to BoNT-B as well $(75,76)$.

Neutralizing antibodies depletion by repeated plasma exchange in one patient with SNR, allowed recovery of BoNT-A treatment effect (77).

\section{Conclusion and Recommendations}

It is suggested that keeping the treatment intervals constant may lead to early detection of SNR (level U).

Repeated plasma exchange is possibly effective in contrasting NAB-induced SNR (level U).

Switching to treatment with BoNT-B produces only temporary recovery of effect, often followed by development of antibodies against BoNT-B (level U).

\section{Management of Side Effects of BoNT Treatment (Table 4) What Is the Most Effective Strategy to Avoid Dysphagia following BoNT Treatment?}

Swallowing difficulty is caused by BoNT spreading to the throat muscles. Bilateral sternocleidomastoid injections are more frequently associated with dysphagia (54). Dysphagia is often mild (severe in $<5 \%$ of the cases), very rarely requires hospitalization or feeding tube, and disappears gradually after 2-3 weeks (54). Dysphagia is relatively common: $7.1 \%$ of the patients reported dysphagia after treatment with the original onabotulinumtoxinA, $3.4 \%$ with the new generation onabotulinumtoxin A, 19.4\% with abobotulinumtoxin A, 12.6\% with incobotulinumtoxinA, and $15.6 \%$ with rimabotulinumtoxinB $(26,44,78)$. Different tendency to spread into surrounding muscles could rely on differences in formulation, size of the protein molecules, or dilution factor, although these results are based on heterogeneous studies in terms of patient selection, dose, and injected muscles (44).

In a study, five CD patients who had reported 34 episodes of dysphagia over 98 EMG-guided injections (34.7\%) were treated with additional use of ultrasounds: this resulted in no episodes of dysphagia across 27 injection sessions (79).

\section{Conclusion and Recommendations}

The additional use of ultrasound may lessen recurrent dysphagia after botulinum treatment (class IV, level U). 
TABLE 4 | Side effects and contraindications of BoNT treatment for CD.

\begin{tabular}{|c|c|c|}
\hline $\begin{array}{l}\text { What is the most effective } \\
\text { to avoid dysphagia? }\end{array}$ & $\begin{array}{l}\text { The additional use of ultrasound may } \\
\text { lessen recurrent dysphagia }\end{array}$ & $U$ \\
\hline $\begin{array}{l}\text { What is the most effective } \\
\text { strategy in case of neck } \\
\text { muscles paresis? }\end{array}$ & $\begin{array}{l}\text { The use of a soft collar can relieve the } \\
\text { symptoms of neck extensor muscles } \\
\text { paresis }\end{array}$ & $U$ \\
\hline $\begin{array}{l}\text { What is the most effective } \\
\text { strategy to prevent } \\
\text { injection pain? }\end{array}$ & $\begin{array}{l}\text { Skin cooling or local application of } \\
\text { anesthetic cream reduce injection pain }\end{array}$ & $U$ \\
\hline $\begin{array}{l}\text { Is BoNT treatment safe } \\
\text { during pregnancy and } \\
\text { lactation? }\end{array}$ & $\begin{array}{l}\text { BoNT treatment during pregnancy and } \\
\text { lactation is not recommended and should } \\
\text { be avoided whenever possible }\end{array}$ & $U$ \\
\hline $\begin{array}{l}\text { Is BoNT treatment safe } \\
\text { for CD patients who use } \\
\text { anticoagulants? }\end{array}$ & $\begin{array}{l}\text { The risk of hematoma following BoNT } \\
\text { treatment by concomitant use of coumarin } \\
\text { derivatives is low }\end{array}$ & $U$ \\
\hline $\begin{array}{l}\text { Is BoNT treatment safe } \\
\text { for CD patients with } \\
\text { concomitant neurological } \\
\text { comorbidities? }\end{array}$ & $\begin{array}{l}\text { Patients with concomitant impairment } \\
\text { of neuromuscular transmission may } \\
\text { experience clinical deterioration after BoNT } \\
\text { treatment, although in selected cases } \\
\text { treatment might be safe and beneficial }\end{array}$ & $U$ \\
\hline
\end{tabular}

BoNT, botulinum neurotoxin; $C D$, cervical dystonia.

\section{What Is the Most Effective Strategy in Case of Neck Muscles Paresis following BoNT Treatment?}

Weakness of the neck extensors is a common side effect of BoNT treatment in these muscles. The symptoms are usually mild and are generally resolved within a few weeks (54). According to a systematic review, this side effect was reported by $62 / 339(18 \%)$ of the patients treated with onabotulinumtoxinA or abobotulinumtoxinA, compared with $9 / 266$ (3\%) of the patients in the placebo group (80). In an RCT on 233 patients, neck weakness was reported in $6-10 \%$ of patients treated with incobotulinumtoxinA 120 or $240 \mathrm{IU}$, respectively, as compared to $1 \%$ of patients treated with placebo (26).

There is no evidence to support the use of a soft collar, although this measure can relieve symptoms of paresis (4).

\section{Conclusion and Recommendations}

The use of a soft collar can relieve the symptoms of neck extensor muscles paresis (class IV, level U).

\section{What Is the Most Effective Strategy to Prevent Pain at the Injection Site?}

In RCTs comparing BoNT-A treatment to placebo, injection pain occurs equally in both groups (4). This pain is usually present for only a few days and is rarely a reason to terminate the BoNT-A treatment (54).

Skin cooling (with ethylchloride spray, dry cold, or ice) or local application of anesthetic cream decreases pain associated with limb or facial botulinum injections (81-83). As such, they may be beneficial in patients for the treatment of $\mathrm{CD}$ too, although no specific studies were found.

\section{Conclusion and Recommendations}

Skin cooling or local application of anesthetic cream can reduce injection pain (class IV, level U).

\section{Contraindications for BoNT Treatment (Table 4) Is BoNT Treatment Safe during Pregnancy and Lactation?}

OnabotulinumtoxinA is classified as pregnancy Category $\mathrm{C}$ by FDA: "Animal reproduction studies have shown an adverse effect on the fetus and there are no adequate and well-controlled studies in humans, but potential benefits may warrant use of the drug in pregnant women despite potential risks. This drug should be used during pregnancy only if the benefit outweighs the risk to the fetus." Animal studies have provided no indications of harm during pregnancy with doses of BoNT-A normally used in clinical practice (84).

Results of a survey on 396 doctors showed that a total of 16 pregnant women had been treated with BoNT, primarily in the first trimester. One patient (8.3\%) had a miscarriage, while the other patients gave birth to healthy children after full-term pregnancies (85). The overall risk of miscarriage, regardless of the cause, is $15-20 \%$ (86). In the literature, up to 25 women are described who have been treated during each stage of pregnancy: two miscarriages were reported in women with previous history of miscarriage; the other cases reported uneventful pregnancy and healthy children (87).

No studies were found on the use of BoNT during lactation. Due to insufficient data, the manufacturers do not recommend using BoNT during lactation, although it seems unlikely that BoNT may enter breast milk (84).

\section{Conclusion and Recommendations}

Although several cases have been reported of safe use of BoNT during pregnancy, the effect of BoNT on the unborn child has been insufficiently studied in humans; therefore, BoNT treatment during pregnancy is not recommended and should be avoided whenever possible (class IV, level U).

No studies have been conducted on the effect of BoNT on the nursing child; to exclude side effects, BoNT treatment should be avoided during lactation (class IV, level U).

\section{Is BoNT Treatment Safe for CD Patients Who Use Anticoagulants?}

No reports of complications resulting from the use of coumarin derivatives or non-vitamin $\mathrm{K}$ antagonist oral anticoagulants by $\mathrm{CD}$ patients treated with BoNT were found. According to the SPC of coumarin derivates, intramuscular injections are discouraged (but not explicitly forbidden) because of the increased risk of hematomas, while no limitation is reported for subcutaneous injections. The incidence of hematoma after BoNT injection was marginally increased in a group of 32 patients treated with phenprocoumon (3\%) with respect to 32 control patients (1.8\%) (88).

\section{Conclusion and Recommendations}

The risk of hematoma following BoNT treatment by concomitant use of coumarin derivatives has not been sufficiently studied but seems low (class IV, level U).

\section{Is BoNT Treatment Safe for CD Patients with Concomitant Neurological Comorbidities?}

Treatment with BoNT may exacerbate symptoms of coexistent neuromuscular diseases $(89,90)$ or unmask subclinical cases $(91,92)$. Myasthenia gravis, amyotrophic lateral sclerosis, 
and Lambert-Eaton diseases are reported as contraindications to BoNTs treatment in the respective SPCs, although cases of safe CD treatment in patients with myasthenia or amyotrophic lateral sclerosis have occasionally been reported $(93,94)$.

Generalized weakness has been rarely reported after BoNT injections, most frequently in patients treated for spasticity $(95,96)$.

\section{Conclusion and Recommendations}

Patients with preexistent impairment of neuromuscular transmission may experience clinical deterioration after BoNT treatment, although in selected cases treatment might be safe and beneficial (class IV, level U).

\section{GENERAL CONSIDERATIONS}

Overall, there is a solid bulk of evidence supporting a good beneficial effect of the different formulations of BoNT in the treatment of $\mathrm{CD}$, with a good benefit-to-risk ratio and a sustained effect over time. However, there is still room for strategies to further improve the efficacy and safety of this treatment. Robust evidence is missing concerning some practical aspects, such as treatment approaches, and the use of supportive techniques including EMG or ultrasounds. Existing knowledge often comes from secondary outcome measures in larger studies designed for other research questions. These studies often use variable methods and outcome measures, which makes comparisons difficult. Future studies should focus on these topics, by using standardized approaches and focusing on only one research question.

It has been noticed that the reported results are not always applicable to the daily practice. This may partly be due to the fact that, in the case of BoNT, optimal treatment requires some variability, according to the needs of the patients and to the progression of the symptoms. The design of future studies should also take this aspect into account.

Although the incidence of adverse events related to BoNT injections, including the formation of NAB, is low, there is a need for established strategies to prevent or manage common side effects of this treatment. To this end, multicentre collaborations are warranted in order to be able to collect an informative number of cases.

\section{REFERENCES}

1. Steeves TD, Day L, Dykeman J, Jette N, Pringsheim T. The prevalence of primary dystonia: a systematic review and meta-analysis. Mov Disord (2012) 27:1789-96. doi:10.1002/mds.25244

2. Klingelhoefer L, Martino D, Martinez-Martin P, Sauerbier A, Rizos A, Jost $\mathrm{W}$, et al. Nonmotor symptoms and focal cervical dystonia: observations from 102 patients. Basal Ganglia (2014) 4:117-20. doi:10.1016/j.baga.2014.10.002

3. Lencer R, Steinlechner S, Stahlberg J, Rehling H, Orth M, Baeumer T, et al. Primary focal dystonia: evidence for distinct neuropsychiatric and personality profiles. J Neurol Neurosurg Psychiatry (2009) 80:1176-9. doi:10.1136/ jnnp.2008.170191

4. Novak I, Campbell L, Boyce M, Fung VS; Cerebral Palsy Institute. Botulinum toxin assessment, intervention and aftercare for cervical dystonia and other causes of hypertonia of the neck: international consensus statement. Eur J Neurol (2010) 17(Suppl 2):94-108. doi:10.1111/j.1468-1331.2010.03130.x

5. Brans JW, Lindeboom R, Snoek JW, Zwarts MJ, Van Weerden TW, Brunt $\mathrm{ER}$, et al. Botulinum toxin versus trihexyphenidyl in cervical dystonia: a
Some of the main clinical questions, including the dose equivalence between different formulations and the minimum safe treatment intervals, are matter of discussion already for several years. This knowledge gap could only be addressed by research groups willing to engage in well designed and adequately powered clinical studies.

The continuous commitment of clinicians and basic scientist to produce robust evidence concerning these and other open questions arising from the clinical practice, is fundamental to improve QoL of CD patients.

\section{AUTHOR CONTRIBUTIONS}

All authors made substantial contributions to the conception of the work, drafted sessions of the manuscript or revised it critically for important intellectual content, gave final approval of the version to be published, and agree to be accountable for all aspects of the work.

\section{ACKNOWLEDGMENTS}

The authors are grateful to Rene Spijker (Medical Library, Academic Medical Center, Amsterdam; Dutch Cochrane Centre, University Medical Center Utrecht) for assistance with the evidence-based literature review.

\section{FUNDING}

This work was supported by European Cooperation in Science and Technology (COST) Action BM1101 "European network for the study of dystonia syndromes." The sponsor facilitated the meeting of the experts but had no role in study design; in the collection, analysis, and interpretation of data; in the writing of the report; and in the decision to submit the article for publication.

\section{SUPPLEMENTARY MATERIAL}

The Supplementary Material for this article can be found online at http://journal.frontiersin.org/article/10.3389/fneur.2017.00035/ full\#supplementary-material.

prospective, randomized, double-blind controlled trial. Neurology (1996) 46:1066-72. doi:10.1212/WNL.46.4.1066

6. Fasano A, Bove F, Lang AE. The treatment of dystonic tremor: a systematic review. J Neurol Neurosurg Psychiatry (2014) 85:759-69. doi:10.1136/ jnnp-2013-305532

7. Jankovic J, Beach J. Long-term effects of tetrabenazine in hyperkinetic movement disorders. Neurology (1997) 48:358-62. doi:10.1212/WNL.48.2.358

8. De Pauw J, Van Der Velden K, Meirte J, Van Daele U, Truijen S, Cras P, et al. The effectiveness of physiotherapy for cervical dystonia: a systematic literature review. J Neurol (2014) 261:1857-65. doi:10.1007/s00415-013-7220-8

9. Munchau A, Palmer JD, Dressler D, O’sullivan JD, Tsang KL, Jahanshahi $\mathrm{M}$, et al. Prospective study of selective peripheral denervation for botulinum-toxin resistant patients with cervical dystonia. Brain (2001) 124:769-83. doi:10.1093/brain/124.4.769

10. Contarino MF, Van Den Munckhof P, Tijssen MA, De Bie RM, Bosch DA, Schuurman PR, et al. Selective peripheral denervation: comparison with pallidal stimulation and literature review. J Neurol (2014) 261:300-8. doi:10.1007/s00415-013-7188-4 
11. Volkmann J, Mueller J, Deuschl G, Kuhn AA, Krauss JK, Poewe W, et al. Pallidal neurostimulation in patients with medication-refractory cervical dystonia: a randomised, sham-controlled trial. Lancet Neurol (2014) 13:875-84. doi:10.1016/S1474-4422(14)70143-7

12. Schjerling L, Hjermind LE, Jespersen B, Madsen FF, Brennum J, Jensen SR, et al. A randomized double-blind crossover trial comparing subthalamic and pallidal deep brain stimulation for dystonia. J Neurosurg (2013) 119:1537-45. doi:10.3171/2013.8.JNS13844

13. Rossetto O, Pirazzini M, Montecucco C. Botulinum neurotoxins: genetic, structural and mechanistic insights. Nat Rev Microbiol (2014) 12:535-49. doi:10.1038/nrmicro3295

14. French J, Gronseth G. Lost in a jungle of evidence: we need a compass. Neurology (2008) 71:1634-8. doi:10.1212/01.wnl.0000336533.19610.1b

15. Tsui JKC, Stoessl AJ, Eisen A, Calne S, Calne DB. Double-blind-study of botulinum toxin in spasmodic torticollis. Lancet (1986) 2:245-7. doi:10.1016/ S0140-6736(86)92070-2

16. Koller W, Vetere-Overfield B, Gray C, Dubinsky R. Failure of fixed-dose, fixed muscle injection of botulinum toxin in torticollis. Clin Neuropharmacol (1990) 13:355-8. doi:10.1097/00002826-199008000-00011

17. Lorentz IT, Subramaniam SS, Yiannikas C. Treatment of idiopathic spasmodic torticollis with botulinum toxin A: a double-blind study on twenty-three patients. Mov Disord (1991) 6:145-50. doi:10.1002/mds.870060210

18. Moore AP, Blumhardt LD. A double blind trial of botulinum toxin "A" in torticollis, with one year follow up. J Neurol Neurosurg Psychiatry (1991) 54:813-6. doi:10.1136/jnnp.54.9.813

19. Lu CS, Chen RS, Tsai CH. Double-blind, placebo-controlled study of botulinum toxin injections in the treatment of cervical dystonia. J Formos Med Assoc (1995) 94:189-92.

20. Lew MF, Adornato BT, Duane DD, Dykstra DD, Factor SA, Massey JM, et al. Botulinum toxin type B: a double-blind, placebo-controlled, safety and efficacy study in cervical dystonia. Neurology (1997) 49:701-7. doi:10.1212/ WNL.49.3.701

21. Poewe W, Deuschl G, Nebe A, Feifel E, Wissel J, Benecke R, et al. What is the optimal dose of botulinum toxin $\mathrm{A}$ in the treatment of cervical dystonia? Results of a double blind, placebo controlled, dose ranging study using Dysport. German Dystonia Study Group. J Neurol Neurosurg Psychiatry (1998) 64:13-7. doi:10.1136/jnnp.64.1.13

22. Brashear A, Lew MF, Dykstra DD, Comella CL, Factor SA, Rodnitzky RL, et al. Safety and efficacy of NeuroBloc (botulinum toxin type B) in type A-responsive cervical dystonia. Neurology (1999) 53:1439-46. doi:10.1212/ WNL.53.7.1439

23. Brin MF, Lew MF, Adler CH, Comella CL, Factor SA, Jankovic J, et al. Safety and efficacy of NeuroBloc (botulinum toxin type B) in type A-resistant cervical dystonia. Neurology (1999) 53:1431-8. doi:10.1212/ WNL.53.7.1431

24. Truong D, Duane DD, Jankovic J, Singer C, Seeberger LC, Comella CL, et al. Efficacy and safety of botulinum type A toxin (Dysport) in cervical dystonia: results of the first US randomized, double-blind, placebo-controlled study. Mov Disord (2005) 20:783-91. doi:10.1002/mds.20403

25. Charles D, Brashear A, Hauser RA, Li HI, Boo LM, Brin MF, et al. Efficacy, tolerability, and immunogenicity of onabotulinumtoxinA in a randomized, double-blind, placebo-controlled trial for cervical dystonia. Clin Neuropharmacol (2012) 35:208-14. doi:10.1097/WNF.0b013e $31826538 \mathrm{c} 7$

26. Comella CL, Jankovic J, Truong DD, Hanschmann A, Grafe S; U.S. XEOMIN Cervical Dystonia Study Group. Efficacy and safety of incobotulinumtoxinA (NT 201, XEOMIN(R), botulinum neurotoxin type A, without accessory proteins) in patients with cervical dystonia. J Neurol Sci (2011) 308:103-9. doi:10.1016/j.jns.2011.05.041

27. Evidente VG, Fernandez HH, Ledoux MS, Brashear A, Grafe S, Hanschmann A, et al. A randomized, double-blind study of repeated incobotulinumtoxinA $\left(\right.$ Xeomin $\left.^{\circledR}\right)$ in cervical dystonia. J Neural Transm (Vienna) (2013) 120:1699-707. doi:10.1007/s00702-013-1048-3

28. Mordin M, Masaquel C, Abbott C, Copley-Merriman C. Factors affecting the health-related quality of life of patients with cervical dystonia and impact of treatment with abobotulinumtoxinA (Dysport): results from a randomised, double-blind, placebo-controlled study. BMJ Open (2014) 4:e005150. doi:10.1136/bmjopen-2014-005150

29. Snaith A, Wade D. Dystonia. BMJ Clin Evid (2014).
30. Comella CL, Jankovic J, Shannon KM, Tsui J, Swenson M, Leurgans S, et al. Comparison of botulinum toxin serotypes $\mathrm{A}$ and $\mathrm{B}$ for the treatment of cervical dystonia. Neurology (2005) 65:1423-9. doi:10.1212/01. wnl.0000183055.81056.5c

31. Pappert EJ, Germanson T; Myobloc/Neurobloc European Cervical Dystonia Study Group. Botulinum toxin type B vs. type A in toxin-naive patients with cervical dystonia: randomized, double-blind, noninferiority trial. Mov Disord (2008) 23:510-7. doi:10.1002/mds.21724

32. Tintner R, Gross R, Winzer U, Smalky K, Jankovic J. Autonomic function after botulinum toxin type A or B: a double-blind, randomized trial. Neurology (2005) 65:765-7. doi:10.1212/01.wnl.0000174433.76707.8c

33. Dressler D, Tacik P, Adib Saberi F. Botulinum toxin therapy of cervical dystonia: comparing onabotulinumtoxin $\mathrm{A}\left(\right.$ Botox $\left.^{\circledR}\right)$ and incobotulinumtoxinA (Xeomin ${ }^{\circledast}$ ). J Neural Transm (Vienna) (2014) 121:29-31. doi:10.1007/ s00702-013-1076-Z

34. Krack P, Deuschl G, Benecke R, Ceballos-Baumann AO, Marion MH, Oertel WH, et al. Dose standardization of botulinum toxin. Mov Disord (1998) 13:749-51. doi:10.1002/mds.870130425

35. Rystedt A, Nyholm D, Naver H. Clinical experience of dose conversion ratios between 2 botulinum toxin products in the treatment of cervical dystonia. Clin Neuropharmacol (2012) 35:278-82. doi:10.1097/WNF.0b013e $3182711 \mathrm{fc} 0$

36. Wohlfarth K, Schwandt I, Wegner F, Jurgens T, Gelbrich G, Wagner A, et al. Biological activity of two botulinum toxin type A complexes (Dysport and Botox) in volunteers: a double-blind, randomized, dose-ranging study. J Neurol (2008) 255:1932-9. doi:10.1007/s00415-008-0031-7

37. Odergren T, Hjaltason H, Kaakkola S, Solders G, Hanko J, Fehling C, et al. A double blind, randomised, parallel group study to investigate the dose equivalence of Dysport and Botox in the treatment of cervical dystonia. J Neurol Neurosurg Psychiatry (1998) 64:6-12. doi:10.1136/jnnp. 64.1.6

38. Ranoux D, Gury C, Fondarai J, Mas JL, Zuber M. Respective potencies of Botox and Dysport: a double blind, randomised, crossover study in cervical dystonia. J Neurol Neurosurg Psychiatry (2002) 72:459-62.

39. Yun JY, Kim JW, Kim HT, Chung SJ, Kim JM, Cho JW, et al. Dysport and Botox at a ratio of 2.5:1 units in cervical dystonia: a double-blind, randomized study. Mov Disord (2015) 30:206-13. doi:10.1002/mds.26085

40. Benecke R, Jost WH, Kanovsky P, Ruzicka E, Comes G, Grafe S. A new botulinum toxin type A free of complexing proteins for treatment of cervical dystonia. Neurology (2005) 64:1949-51. doi:10.1212/01.WNL.0000163767. 99354.C3

41. Wissel J, Kanovsky P, Ruzicka E, Bares M, Hortova H, Streitova H, et al. Efficacy and safety of a standardised 500 unit dose of Dysport (clostridium botulinum toxin type A haemagglutinin complex) in a heterogeneous cervical dystonia population: results of a prospective, multicentre, randomised, double-blind, placebo-controlled, parallel group study. J Neurol (2001) 248:1073-8.

42. Brans JW, De Boer IP, Aramideh M, Ongerboer de Visser BW, Speelman JD. Botulinum toxin in cervical dystonia: low dosage with electromyographic guidance. J Neurol (1995) 242:529-34. doi:10.1007/BF00867425

43. Boghen D, Flanders M. Effectiveness of botulinum toxin in the treatment of spasmodic torticollis. Eur Neurol (1993) 33:199-203. doi:10.1159/000116936

44. Chapman MA, Barron R, Tanis DC, Gill CE, Charles PD. Comparison of botulinum neurotoxin preparations for the treatment of cervical dystonia. Clin Ther (2007) 29:1325-37. doi:10.1016/j.clinthera.2007.07.020

45. Poewe W, Deuschl G, Nebe A, Feifel E, Wissel J, Benecke R, et al. What is the optimal dose of botulinum toxin A in the treatment of cervical dystonia? Results of a double blind, placebo controlled, dose ranging study using Dysport (R). J Neurol Neurosurg Psychiatry (1998) 64:13-7. doi:10.1136/ jnnp.64.1.13

46. Comella CL, Buchman AS, Tanner CM, Browntoms NC, Goetz CG Botulinum toxin injection for spasmodic torticollis - increased magnitude of benefit with electromyographic assistance. Neurology (1992) 42:878-82. doi:10.1212/WNL.42.4.878

47. Werdelin L, Dalager T, Fuglsang-Frederiksen A, Regeur L, Karlsborg M, Korbo L, et al. The utility of EMG interference pattern analysis in botulinum toxin treatment of torticollis: a randomised, controlled and blinded study. Neurophysiol Clin (2011) 122:2305-9. doi:10.1016/j.clinph.2011. 04.012 
48. Brans JW, Aramideh M, Koelman JH, Lindeboom R, Speelman JD, Ongerboer de Visser BW. Electromyography in cervical dystonia: changes after botulinum and trihexyphenidyl. Neurology (1998) 51:815-9. doi:10.1212/ WNL.51.3.815

49. Van Gerpen JA, Matsumoto JY, Ahlskog JE, Maraganore DM, Mcmanis PG. Utility of an EMG mapping study in treating cervical dystonia. Muscle Nerve (2000) 23:1752-6. doi:10.1002/1097-4598(200011)23:11<1752::AIDMUS12>3.3.CO;2-L

50. Nijmeijer SWR, Koelman JHTM, Standaar TSM, Postma M, Tijssen MAJ. Cervical dystonia: improved treatment response to botulinum toxin after referral to a tertiary centre and the use of polymyography. Parkinsonism Relat Disord (2013) 19:533-8. doi:10.1016/j.parkreldis.2013. 01.018

51. Cordivari C, Misra VP, Vincent A, Catania S, Bhatia KP, Lees AJ. Secondary nonresponsiveness to botulinum toxin A in cervical dystonia: The role of electromyogram-guided injections, botulinum toxin a antibody assay, and the extensor digitorum brevis test. Mov Disord (2006) 21:1737-41. doi:10.1002/ mds. 21051

52. Delnooz CCS, Veugen LC, Pasman JW, Lapatki BG, Van Dijk JP, Van De Warrenburg BPC. The clinical utility of botulinum toxin injections targeted at the motor endplate zone in cervical dystonia. Eur J Neurol (2014) 21:1486-e98. doi:10.1111/ene.12517

53. Borodic GE, Pearce LB, Smith K, Joseph M. Botulinum a toxin for spasmodic torticollis: multiple vs single injection points per muscle. Head Neck (1992) 14:33-7. doi:10.1002/hed.2880140108

54. Moore A, Naumann M. Handbook of Botulinum Toxin Treatment. Oxford: Wiley-Blackwell (2003).

55. Boyce MJ, Canning CG, Mahant N, Morris J, Latimer J, Fung VS. Active exercise for individuals with cervical dystonia: a pilot randomized controlled trial. Clin Rehabil (2013) 27:226-35. doi:10.1177/0269215512456221

56. Tassorelli C, Mancini F, Balloni L, Pacchetti C, Sandrini G, Nappi G, et al. Botulinum toxin and neuromotor rehabilitation: an integrated approach to idiopathic cervical dystonia. Mov Disord (2006) 21:2240-3. doi:10.1002/ mds. 21145

57. Queiroz MA, Chien HF, Sekeff-Sallem FA, Barbosa ER. Physical therapy program for cervical dystonia: a study of 20 cases. Funct Neurol (2012) 27:187-92.

58. Dobryansky M, Korsh J, Shen AE, Aliano K. Botulinum toxin type A and B primary resistance. Aesthet Surg J (2015) 35:N28-30. doi:10.1093/asj/ sju027

59. Thompson JA, Glasgow LA, Warpinski JR, Olson C. Infant botulism: clinical spectrum and epidemiology. Pediatrics (1980) 66:936-42.

60. Ferreira JJ, Bhidayasiri R, Colosimo C, Marti MJ, Zakine B, Maisonobe P. Survey of practices employed by neurologists for the definition and management of secondary non-response to botulinum toxin in cervical dystonia. Funct Neurol (2012) 27:225-30.

61. Mohammadi B, Buhr N, Bigalke H, Krampfl K, Dengler R, Kollewe K. A long-term follow-up of botulinum toxin A in cervical dystonia. Neurol Res (2009) 31:463-6. doi:10.1179/174313209X405137

62. Brin MF, Comella CL, Jankovic J, Lai F, Naumann M; CD-017 BoNTA Study Group. Long-term treatment with botulinum toxin type A in cervical dystonia has low immunogenicity by mouse protection assay. Mov Disord (2008) 23:1353-60. doi:10.1002/mds.22157

63. Kranz G, Sycha T, Voller B, Kranz GS, Schnider P, Auff E. Neutralizing antibodies in dystonic patients who still respond well to botulinum toxin type A. Neurology (2008) 70:133-6. doi:10.1212/01.wnl.0000287087. 99612.e5

64. Kessler KR, Skutta M, Benecke R. Long-term treatment of cervical dystonia with botulinum toxin A: efficacy, safety, and antibody frequency. German Dystonia Study Group. J Neurol (1999) 246:265-74. doi:10.1007/ s004150050345

65. Dressler D, Bigalke H. Botulinum toxin type B de novo therapy of cervical dystonia: frequency of antibody induced therapy failure. J Neurol (2005) 252:904-7. doi:10.1007/s00415-005-0774-3

66. Chinnapongse RB, Lew MF, Ferreira JJ, Gullo KL, Nemeth PR, Zhang $\mathrm{Y}$. Immunogenicity and long-term efficacy of botulinum toxin type B in the treatment of cervical dystonia: report of 4 prospective, multicenter trials. Clin Neuropharmacol (2012) 35:215-23. doi:10.1097/WNF.0b013e $318263163 \mathrm{c}$
67. Ferreira JJ, Colosimo C, Bhidayasiri R, Marti MJ, Maisonobe P, Om S. Factors influencing secondary non-response to botulinum toxin type A injections in cervical dystonia. Parkinsonism Relat Disord (2015) 21:111-5. doi:10.1016/j. parkreldis.2014.09.034

68. Benecke R. Clinical relevance of botulinum toxin immunogenicity. BioDrugs (2012) 26:e1-9. doi:10.2165/11599840-000000000-00000

69. Dressler D, Tacik P, Saberi FA. Botulinum toxin therapy of cervical dystonia: duration of therapeutic effects. J Neural Transm (Vienna) (2015) 122:297-300. doi:10.1007/s00702-014-1253-8

70. Greene P, Kang U, Fahn S, Brin M, Moskowitz C, Flaster E. Double-blind, placebo-controlled trial of botulinum toxin injections for the treatment of spasmodic torticollis. Neurology (1990) 40:1213-8. doi:10.1212/ WNL.40.8.1213

71. Greene P, Fahn S, Diamond B. Development of resistance to botulinum toxin type A in patients with torticollis. Mov Disord (1994) 9:213-7. doi:10.1002/ mds. 870090216

72. Sethi KD, Rodriguez R, Olayinka B. Satisfaction with botulinum toxin treatment: a cross-sectional survey of patients with cervical dystonia. J Med Econ (2012) 15:419-23. doi:10.3111/13696998.2011.653726

73. Dressler D. Clinical presentation and management of antibody-induced failure of botulinum toxin therapy. Mov Disord (2004) 19(Suppl 8):S92-100. doi: $10.1002 / \mathrm{mds} .20022$

74. Hefter $\mathrm{H}$, Spiess $\mathrm{C}$, Rosenthal D. Very early reduction in efficacy of botulinum toxin therapy for cervical dystonia in patients with subsequent secondary treatment failure: a retrospective analysis. J Neural Transm (Vienna) (2014) 121:513-9. doi:10.1007/s00702-013-1127-5

75. Dressler D, Bigalke H, Benecke R. Botulinum toxin type B in antibody-induced botulinum toxin type A therapy failure. J Neurol (2003) 250:967-9. doi:10.1007/s00415-003-1129-6

76. Barnes MP, Best D, Kidd L, Roberts B, Stark S, Weeks P, et al. The use of botulinum toxin type- $\mathrm{B}$ in the treatment of patients who have become unresponsive to botulinum toxin type-A - initial experiences. Eur J Neurol (2005) 12:947-55. doi:10.1111/j.1468-1331.2005.01095.x

77. Naumann M, Toyka KV, Mansouri Taleghani B, Ahmadpour J, Reiners K, Bigalke H. Depletion of neutralising antibodies resensitises a secondary non-responder to botulinum A neurotoxin. J Neurol Neurosurg Psychiatry (1998) 65:924-7. doi:10.1136/jnnp.65.6.924

78. Barron RM, Campbell SL, King D, Bellon A, Chapman KE, Williamson RA, et al. High titers of transmissible spongiform encephalopathy infectivity associated with extremely low levels of PrPSc in vivo. J Biol Chem (2007) 282:35878-86. doi:10.1074/jbc.M704329200

79. Hong JS, Sathe GG, Niyonkuru C, Munin MC. Elimination of dysphagia using ultrasound guidance for botulinum toxin injections in cervical dystonia. Muscle Nerve (2012) 46:535-9. doi:10.1002/mus.23409

80. Costa J, Espirito-Santo C, Borges A, Ferreira JJ, Coelho M, Moore P, et al. Botulinum toxin type A therapy for cervical dystonia. Cochrane Database Syst Rev (2005) 1:CD003633.

81. Elibol O, Ozkan B, Hekimhan PK, Caglar Y. Efficacy of skin cooling and EMLA cream application for pain relief of periocular botulinum toxin injection. Ophthal Plast Reconstr Surg (2007) 23:130-3. doi:10.1097/ IOP.0b013e318030459c

82. Fung S, Phadke CP, Kam A, Ismail F, Boulias C. Effect of topical anesthetics on needle insertion pain during botulinum toxin type A injections for limb spasticity. Arch Phys Med Rehabil (2012) 93:1643-7. doi:10.1016/j.apmr.2012.03.012

83. Irkoren S, Ozkan HS, Karaca H. A clinical comparison of EMLA cream and ethyl chloride spray application for pain relief of forehead botulinum toxin injection. Ann Plast Surg (2015) 75:272-4. doi:10.1097/ SAP. 0000000000000121

84. Briggs G, Freeman R, Yaffe S. Drugs in Pregnancy and Lactation. Philadelphia: Lippincott Williams \& Wilkins (2008).

85. Morgan JC, Iyer SS, Moser ET, Singer C, Sethi KD. Botulinum toxin A during pregnancy: a survey of treating physicians. J Neurol Neurosurg Psychiatry (2006) 77:117-9. doi:10.1136/jnnp.2005.063792

86. Wahabi HA, Fayed AA, Esmaeil SA, Al Zeidan RA. Progestogen for treating threatened miscarriage. Cochrane Database Syst Rev (2011) 12:CD005943. doi:10.1002/14651858.CD005943

87. Aranda MA, Herranz A, Del Val J, Bellido S, Garcia-Ruiz P. Botulinum toxin A during pregnancy, still a debate. Eur J Neurol (2012) 19:e81-2. doi:10.1111/j.1468-1331.2012.03775.x 
88. Schrader C, Ebke M, Tacik P, Dressler D. Botulinum toxin therapy in patients with oral anticoagulation: hematoma frequency vs. other side effects. J Neural Transm (2013) 120:1154

89. Dressler D. Botulinum toxin for treatment of dystonia. Eur J Neurol (2010) 17(Suppl 1):88-96. doi:10.1111/j.1468-1331.2010.03058.x

90. Watts J, Brew B, Tisch S. Myasthenia gravis exacerbation with low dose ocular botulinum toxin for epiphoria. J Clin Neurosci (2015) 22:1979-81. doi:10.1016/j.jocn.2015.05.032

91. Tarsy D, Bhattacharyya N, Borodic G. Myasthenia gravis after botulinum toxin A for Meige syndrome. Mov Disord (2000) 15:736-8. doi:10.1002/1531-8257(200007)15:4<736::AID-MDS1023>3.0.CO;2-9

92. Iwase T, Iwase C. Systemic effect of local and small-dose botulinum toxin injection to unmask subclinical myasthenia gravis. Graefes Arch Clin Exp Ophthalmol (2006) 244:415-6. doi:10.1007/s00417-005-0130-4

93. Goncalves MR, Barbosa ER, Zambon AA, Marchiori PE. Treatment of cervical dystonia with botulinum toxin in a patient with myasthenia gravis. Arq Neuropsiquiatr (1999) 57:683-5. doi:10.1590/S0004-282X1999000400024

94. Fasano A, Bentivoglio AR, Ialongo T, Soleti F, Evoli A. Treatment with botulinum toxin in a patient with myasthenia gravis and cervical dystonia. Neurology (2005) 64:2155-6. doi:10.1212/01.WNL.0000165997.77985.32

95. Coban A, Matur Z, Hanagasi HA, Parman Y. Iatrogenic botulism after botulinum toxin type A injections. Clin Neuropharmacol (2010) 33:158-60. doi:10.1097/WNF.0b013e3181d479e0

96. Crowner BE, Torres-Russotto D, Carter AR, Racette BA. Systemic weakness after therapeutic injections of botulinum toxin A: a case series and review of the literature. Clin Neuropharmacol (2010) 33:243-7. doi:10.1097/ WNF.0b013e3181f5329e

Conflict of Interest Statement: JS, YB, MR, JD, and EZ declare no conflict of interest. MC: advisory board: Medtronic and Boston Scientific. Is coinventor on a patent application relevant to deep brain stimulation? Speaking fees: Abbvie, Medtronic, Boston Scientific, and ECMT. KB: receives royalties from publication of Oxford Specialist Handbook of Parkinson's Disease and Other
Movement Disorders (Oxford University Press, 2008) and of Marsden's Book of Movement Disorders (Oxford University Press, 2012). He receives a stipend as coeditor of Movement disorders Clinical Practice journal. He received honoraria and/or funding for travel to speak at educational meetings/conferences from Teva-Lundbeck, Ipsen, Allergan, and Merz Pharmaceuticals. He has been paid honoraria to be on advisory board for Ipsen and Allergan companies. NG: grants and personal fees from Teva-Lundbeck, IntecPharma, and NeuroDerm; personal fees from Armon Neuromedical Ltd.IDexel, Monfort, Pharma Two B, UCB, Novartis, Abbvie, Shaier, Genzyme, Dexel, and Sionara; grants, personal fees and other from Lysosomal Therapeutic Inc; outside the submitted work. In addition, NG has a patent concerning parkinsonian monitoring by body fixed sensors of motion and behavior pending. JK: received research and educational grants from Ipsen and Allergan. AL: speaking fee: Ipsen and Nordicinfu Care. Congress participation funded: Abbvie. MM: received speaking fees from Ipsen, Merz, Allergan, and UCB. MP: travel support from Dystonia Foundation. MS: speakers honoraria and compensations for consultations from Abbvie, Actavis, Egis, Krka, Lundbeck, Medtronic, Teva, and UCB. JF: consultancies: GlaxoSmithKline, Novartis, Teva, Lundbeck, Solvay, Abbott, BIAL, Merck-Serono, Merz, Ipsen, and Biogen. Grants: GlaxoSmithKline, Grunenthal, Fundação MSD (Portugal), Teva, MSD, Allergan, Novartis. Other: BIAL, Biogen. MV: advisory board: Merz. AA: speaker's honoraria from Ipsen, Merz, Medtronic, Boston Scientific, UCB, and Abbvie. MT: received educational grants and national DystonieNet grants from Ipsen, Allergan Pharmaceutics, Merz, Medtronic, and Actelion.

Copyright (๔) 2017 Contarino, Van Den Dool, Balash, Bhatia, Giladi, Koelman, Lokkegaard, Marti, Postma, Relja, Skorvanek, Speelman, Zoons, Ferreira, Vidailhet, Albanese and Tijssen. This is an open-access article distributed under the terms of the Creative Commons Attribution License (CC BY). The use, distribution or reproduction in other forums is permitted, provided the original author (s) or licensor are credited and that the original publication in this journal is cited, in accordance with accepted academic practice. No use, distribution or reproduction is permitted which does not comply with these terms. 